\title{
The Characteristics of Digital Entrepreneurship and Digital Transformation: A Systematic Literature Review
}

\author{
Joshua Antonizzi and Hanlie Smuts ${ }^{(\bowtie)}(\mathbb{D}$ \\ Department of Informatics, University of Pretoria, Pretoria, South Africa \\ ul5052682@tuks.co.za, hanlie.smuts@up.ac.za
}

\begin{abstract}
The characteristics of digital entrepreneurship and digital transformation and how they are related, is complex and important to understand in this digital age. Such an understanding of digital entrepreneurship is perceived as a key pillar for economic growth, job creation and innovation. However, a number of issues regarding digital entrepreneurship and digital transformation are prevalent, inhibiting digital entrepreneurs to optimise the advantages that digital entrepreneurship contributes towards business value. Therefore, the aim of this research paper is to investigate digital entrepreneurship and digital transformation, their characteristics and inter-relationships. Data extracted and analysed through a structured analysis process, recognises and discusses the characteristics of digital entrepreneurship and digital transformation. The characteristics are reported by employing the Dynamic Capabilities Theory as the structure. By understanding the characteristics of digital entrepreneurship and digital transformation, individuals and organisations may either create new business ventures or transform existing businesses through the development of novel digital technologies or the innovative application of such technologies.
\end{abstract}

Keywords: Digital entrepreneurship $\cdot$ Digital transformation

\section{Introduction}

Entrepreneurship, in its simplest form, can be described as self-employment [1]. Digital entrepreneurship, on the other hand, diverges from this definition seeing as it involves entrepreneurial pursuits which occur on a digital platform [2]. Digital entrepreneurs have a reliance on digital media tools and Information Technology (IT) in the pursuit of entrepreneurial prospects [2]. Digital entrepreneurship ensues when an asset owned by a business, a service performed by a business or a fundamental element of a business has been digitised [3]. Digital entrepreneurship expands on the traditional notion of entrepreneurship in the sense that it includes a set of participants which is constantly evolving and is highly diverse [4]. This moves away from the traditional, established participant to a more ever-changing assemblage of participants who possess their own, and differing, competencies, aspirations, and, ultimately, purposes [3, 4].

Furthermore, digital entrepreneurship is deeply entrenched in digital opportunity [5]. The rate of technological development is at an all-time, ever-increasing high, and 
digital entrepreneurs are mindful of the opportunities that this growth is creating $[5,6]$. To capitalise on these opportunities, entrepreneurs are looking towards digital transformation. Digital transformation can be defined as companies who alter their operations, and, in broader terms, it can also refer to the persistent change of our civilization through the use of technology [6,7]. Digital transformation involves the redesign of business practices to incorporate digital technology within all facets of the business [7]. Digital entrepreneurs are offered significant opportunity through the use of digital networking capabilities. These opportunities present themselves through users of digital mediums who can now be offered support, can respond to messages and can offer constructive criticism and suggestions which organisations can utilize [3].

However, there are a number of concerns surrounding digital entrepreneurship and digital transformation. Using business processes and capabilities to achieve the wants of customers is of paramount importance to up-and-coming companies and their digital entrepreneurs [3, 8]. Digitisation spanning all functions and operations of a business can be considered more and more difficult the larger the organisation $[3,8]$. The practice of large companies updating obsolete and outdated business systems to modernized, digital systems can be problematic owing to the irregularities found within these systems [9]. Other challenges related to digital transformation point to occurrences where existing business models generate sufficient profit to ward off the need for establishing new, digitised products and services for clients to purchase [10].

Consequently, the main purpose of this study is to explore the following primary research question: "What are the characteristics of the relationship between digital entrepreneurship and digital transformation?" By considering such a digital entrepreneurship scope, digital entrepreneurs may optimise the advantages that digital transformation brings towards achieving business value.

The remainder of the paper is structured as follows: in Sect. 2 we provide the background to the study presenting an overview of digital entrepreneurship (Sect. 2.1), digital transformation (Sect. 2.2), and their interrelationship (Sect. 2.3). The approach to this study is discussed in Sect. 3, where after we provide an overview of the findings in Sect. 4. In Sect. 5, we present the framework for digital entrepreneurship enabled through digital transformation and we conclude the study in Sect. 6.

\section{Background}

The nature of digital entrepreneurship based businesses is that of both IT and traditional business knowledge. This translates to entrepreneurs requiring both technical and business-related knowledge and skills, which is a duel-mastery, and not easily acquired $[11,12]$. Two types of entrepreneurs are prevalent $[11,13]$. The first type of entrepreneur is that of the research-based entrepreneur that commercialises original technological discoveries. The second kind of entrepreneur is an imitative entrepreneur that develops present markets by assembling available organisational resources [13]. Digital entrepreneurs have been found to have a reliance on digital media tools and Information Technology (IT) in the pursuit of entrepreneurial prospects [11]. As a result, the digital economy is suffering as digital entrepreneurs are intensifying the rivalries between industry participants [14]. This means that digital entrepreneurs can fall within 
the classification of research-based or imitation entrepreneurs, who simply make use of digital media in the pursuit of other, broader entrepreneurial opportunities $[11,12]$.

Scholars cite a number of barriers that prevent this pursuit of entrepreneurial opportunities; excessive amounts of data which cannot be properly processed, a distinct lack of training on business knowledge and digital skills, disproportionate competition and competitor-drenched markets as well as a lack of investor interest or inability to attain capital [15]. Finally, exorbitant cost to start-up and the inability to keep up with disruption factors and costs, needs to be addressed when considering digital entrepreneurship $[15,16]$.

In the next sections we explore digital entrepreneurship and digital transformation in more detail, as well as the relationship between these two concepts.

\subsection{Digital Entrepreneurship}

Digital entrepreneurship can be defined as entrepreneurial opportunities being created and pursued through the use of technological platforms and other information communicating equipment [2, 14]. Therefore, digital entrepreneurship may fall within many categories of business $[1,5]$. As technology advances and cultivates, so too will these categories (e.g. marketing, sales, products, distribution, stakeholder management, operations) and new categories can potentially be fashioned [1, 11].

Another characteristic regarding digital entrepreneurship is that it is multi-faceted and is a combination of business-, knowledge- and institutional entrepreneurship working symbiotically [14]. Business entrepreneurship is a form of entrepreneurship which is most commonly heard-of and discussed. It explains the practice of seeking out or identifying business opportunities which can be exploited [17]. These practices include new product or service creation, raw material identification and use, new industry creation, new forms of business and more [18]. Knowledge entrepreneurship is categorised by the identification and quest for information or knowledge-based prospects and encompasses the expansion of existing knowledge-bases as well as the development of new ones [19]. Institutional entrepreneurship characterises the actions of entrepreneurs who make use of resources in the pursuit of creating new organisations or upgrading old ones [20]. Digital entrepreneurship is subsequently a combination of the above three entrepreneurial practices. Digital entrepreneurs synergistically combine business, institutional and knowledge entrepreneurship and this combination forms the basis of being able to take traditional practices, such as the business categories listed above, and alter them digitally [14, 21].

Owing to the fact that digital entrepreneurship is fundamentally based on digital enablement, digital transformation is presented in the next section.

\subsection{Digital Transformation}

All around the world, companies across all industries are comprehending the importance of digital transformation to the sustainability of their profits and their continued existence and prosperity [6]. Therefore, business functions, such as sales, marketing, human resources, operations, finance, research and development and customer support need to be transformed into the digital environment [7]. Gale and Aarons [22] studied 
companies which had undergone digital transformation and found that they are able to gain competitive advantages by simultaneously lowering their expenses, innovating and becoming more organized and competent. Additionally, true mastery of an organisation's supply-chain activities will arise from digital transformation [23]. As a result of this digital transformation necessity, companies need to design and create strategies in order to make digital transformation possible [6, 7]. A digital business strategy can be described as a corporate strategy designed, created and implemented making use of digital resources to create new and unexploited worth [24].

There are 4 interrelated business transformation strategies, namely: use of technologies, changes in value creation, structural changes as well as financial aspects [25, 26]. Use of technologies speaks to an organisation's technological drive and desire to transform and determines an organisation's opinions about a new IT factor, as well as that particular organisation's willingness and capacity to use it. Changes in value creation describes the effect of digital transformation strategies on the value chains, which presently existed within an organisation and determines the level at which the digitised processes are different from the existing, traditional methods. Structural changes form the foundation of an organisation's ability to transform digitally and make use of new technologies to change their value creation, while financial aspects refers to the requirement of funding and capital that is required for digital transformation to take place $[25,26]$.

Much like the relationship between the above four strategies, digital transformation has a strong, growing relation with digital entrepreneurship. This relationship is explored in the following section.

\subsection{Digital Entrepreneurship and Digital Transformation Interrelationship}

In order to understand the difference between digital entrepreneurship and digital transformation, the supply-side and the demand-side of entrepreneurship needs to be clarified [27]. The supply-side of entrepreneurship encompasses the human element of entrepreneurship. That is, the people who are suitable to take-on entrepreneurial roles and positions. The demand-side encompasses those aforementioned positions; new positions which are available to those entrepreneurs who are willing and able to fill them [27]. This typifies the necessary and present relationship between digital entrepreneurship and digital transformation - digital entrepreneurs can take on roles and responsibilities created through digital transformation, or could create digital transformation themselves [21]. As a result, new disruptive growth for businesses leads to an increase in opportunity for digital entrepreneurs.

Two strategies were developed towards growing new disruptive businesses [28]: firstly, creating a new market as the foundation for the disruption and secondly, disrupting business models which are held by industry leaders. New market creation involves identifying a product or service which satisfies a need which people have, but neither have the time, the energy, the drive nor the resources to do it. It is less complicated and more cost-effective to attract customers who are purchasing nothing than it is to poach or sway customers who are loyal to existing companies or 
competitors. Disrupting business models propose that if a new market cannot be created, an alternative possibility is to enter an existing market and to disrupt it instead [28].

The next section presents an overview of the research methodology followed for this research paper.

\section{Research Approach}

The objective of this paper is to investigate digital entrepreneurship and digital transformation, their characteristics and inter-relationships. In order to achieve this objective, a systematic literature review (SLR) was conducted in order to provide a thorough, impartial amalgam of a number of studies relevant to the topic being researched, collated within one document [29]. An SLR process comprises of 3 consecutive stages: (1) planning, (2) execution and (3) result analysis [30]. Planning involves defining the research objectives and the manner in which the review will be carried out. Execution points to the study selection and the data collection, while result analysis encompasses the data synthesis and results discussion [29, 30]. The planning phase was guided by the aim of the research study, namely, to propose a digital entrepreneurship framework enabled by digital transformation. Technical reports, academic books and specific scientific databases were chosen for the SLR process. The sources considered are shown in Table 1 in the database column as they hold the most important and highest impact full-text journals and conference proceedings in the digital technologies field.

Table 1. Total number of papers found per database

\begin{tabular}{l|c|c|c}
\hline Database & Entrepreneurship & Transformation & Total \\
\hline EBSCOhost & 13 & 40 & 53 \\
\hline Emerald Insight & 16 & 17 & 33 \\
\hline Google Scholar & 30 & 30 & 60 \\
\hline IEEE Xplore & 15 & 15 & 30 \\
\hline SAGE & 2 & 1 & 3 \\
\hline Springer Link & 59 & 15 & 74 \\
\hline Total & 135 & 118 & 253 \\
\hline
\end{tabular}

The following keywords were used to find relevant studies: for Digital Entrepreneurship included ("Digital Entrepreneurship" OR "Digital Business" OR "Digital Entrepreneur*" OR "Digital (NEAR/2) era") AND (skills OR frame* OR strat* OR review OR func* OR fail* OR barriers OR characteristics) NOT transformation. For Digital Transformation the search terms included ("Digital Transformation" OR "Transform* digital" OR "strategic transform*") AND (strat* OR adopt* OR benefits OR barriers OR practices) NOT Entrepreneurship. The initial search produced a list of 253 papers as shown in Table 1. 
The research studies were screened through the application of specific criteria to exclude papers such as studies not associated with the research questions, non-English studies, anecdotal or opinion-based papers and duplicate studies that formed part of the result set. Criteria for inclusion of sources consisted of peer-reviewed publications (journal papers, conference proceedings, books, case studies, book chapters) and technical reports.

After the initial search, the application of exclusion and inclusion criteria, the detailed screening of abstracts and analysis of the full-text of the prospective papers, 30 papers were identified for detailed analysis.

\section{Data Analysis and Findings}

Data was extracted from the selected papers based on the objective of this study, which is to consider the characteristics of digital entrepreneurship and digital transformation. Characteristic in the context of this paper refer to any distinguishing feature or attribute of an item [31]. These distinguishing features or attributes were extracted and reported in Table 2 together with the number of times the same theme occurred (frequency count). For each characteristic identified, the source is indicated.

Self-employment refers to an individual's aspiration of working for him/herself as a freelance employee or the owner of a business, rather than for an employer. Selfemployment is viewed as freedom from traditional work assignments, work hours and undesirable working conditions. Work satisfaction alludes to the measure of person's satisfaction with their job. Work satisfaction could be an important cornerstone of any person's reason to choose what industry to work in, which job they seek or how strongly they wish to be an entrepreneur. Entrepreneurship is a practice which people are drawn to, one which offers the potential for freedom, money, power and personal purpose. Entrepreneurs across all industries, disciplines and practices, have certain traits which set them aside from the rest of the work force such as business opportunity identification and exploitation, vision and overcoming potential barriers. Entrepreneurship can come from a range of areas and opportunities. This particular characteristic was identified from entrepreneurship stemming from circumstances which allowed for entrepreneurship to arise and flourish. These opportunities come in the form of new markets, technological advancements, deficiencies in need satisfaction, price-point vulnerabilities and a variety of other sources which lead to entrepreneurship in multiple forms.

From a digital transformation perspective, digitisation allows for better relationships. Critical to the success of almost all organisations globally is their ability to create, maintain and prioritise relationships, and even more so for entrepreneurs. These are relationships between the entrepreneur and other organisations within and outside of their market, their suppliers, their employees and, most importantly, with their customers; prioritising communication channels with their customer base have significant competitive advantages over their competitors. Digitisation facilitates communication, making it pivotal to the continuing success of an entrepreneur therefore, understanding digitisation is critical. Digitisation, however, does not mean success is automatically and easily attainable. While digitisation offers a range of opportunities to 
Table 2. Characteristic and reference

\begin{tabular}{|c|c|}
\hline Characteristic & Source \\
\hline Self-employment & {$[15,32]$} \\
\hline Work satisfaction & {$[32]$} \\
\hline Entrepreneurship prospect & {$[27]$} \\
\hline Entrepreneurial traits & {$[15-18,27,33]$} \\
\hline Entrepreneurship can come from opportunity & $\begin{array}{l}{[3,14-18,20,21,27,33-} \\
38]\end{array}$ \\
\hline Digitisation allows for better relationships & {$[9,22,23,25,34,35,39]$} \\
\hline $\begin{array}{l}\text { Digitisation does not mean success is clear and easy to } \\
\text { entrepreneurs }\end{array}$ & {$[16]$} \\
\hline Employee involvement is crucial & [40] \\
\hline Knowledge management & {$[19]$} \\
\hline Traditional organisational structures may slow progress & {$[9,23,41]$} \\
\hline E-strategies bolster competitive advantage & {$[42]$} \\
\hline Entrepreneurship aspiration & {$[20,37]$} \\
\hline $\begin{array}{l}\text { Business intelligence can facilitate entrepreneurship and } \\
\text { transformation }\end{array}$ & {$[43]$} \\
\hline Disruption comes from new market creation & $\begin{array}{l}{[14,15,17,22,28,33,34,} \\
38]\end{array}$ \\
\hline Disruption comes from existing markets & $\begin{array}{l}{[17,20,25,28,37,38,40,} \\
44]\end{array}$ \\
\hline Production competence comes from technology & {$[25,34,45,46]$} \\
\hline Costs of technology & {$[22,37,45,46]$} \\
\hline Technology adoption & {$[25,34,45,46]$} \\
\hline $\begin{array}{l}\text { Technology improves compatibility and working between } \\
\text { organisations }\end{array}$ & {$[9,35]$} \\
\hline Understanding digitisation is critical & $\begin{array}{l}{[3,21,22,24,25,39,40,} \\
44]\end{array}$ \\
\hline Digitisation allows for virtual teamwork & {$[21,35]$} \\
\hline
\end{tabular}

entrepreneurs, enacting it is not a guarantee of success to entrepreneurs. There is also an array of other issues which need to be carefully considered, managed and mitigated. There are resource issues, social issues, network requirements, market availability and competitors which will constantly keep entrepreneurs vigilant, regardless of how digitised their organisation has become. Employee involvement is also important as having the best technology, processes, strategies, operations, partners and opportunities in a market cannot add any value if the company has no one to endorse all of these aforementioned strengths. The benefits of any technology can only be realised when it is being truly accepted and utilised. User acceptance of technologies and the influences on user attitudes, customer engagement and business operations have been widely researched, and is a key characteristic enabling digital entrepreneurship. 
Knowledge management involves the creation, control and use of all forms of knowledge throughout an organisation. This is knowledge of systems, customers, employees, strategies, threats, opportunities, and any other form of information which an organisation can be sustained and improved using. Managing and effectively distributing knowledge throughout an organisation is crucial to both maintaining success as well as pioneering expansion. Traditional organisations are heavily structured, rigid bodies which possess a great deal of hierarchy. Upper management and associated strategists decide on the direction of the organisation and dictate that direction to subordinates. This may slow down progress drastically compared to fast-paced, newage companies. E-strategies bolster competitive advantage. As we move further and further into the digital age, e-business strategies are becoming cardinal to successful operations, sustenance and development of all organisations, especially those which primarily operate within the digital realm. Organisations which employ e-strategies are experiencing advantages over competitors who are not engaging in strategies of a similar nature. Adoption can be increased or reduced based on a number of factors. There is a broad spectrum of reasons organisations are either excited or reluctant to adopt new technologies and practices. These reasons include cost, competitive advantage, learning curves, training, revenue potential and all other factors which are relevant to adoption. Entrepreneurship can also come from within. While entrepreneurship is primarily associated with private, self-employed individuals starting companies, it is important to note that entrepreneurship can arise from within an existing organisation. Emerging markets allow for entrepreneurs to go from being employees within an organisation to becoming self-sufficient entrepreneurs, creating new businesses within those markets.

Business intelligence can facilitate entrepreneurship and transformation. Entrepreneurship and transformation is impossible to achieve without data, and more information and, most importantly, knowledge. Business intelligence is the driver behind entrepreneurship and transformation. Business intelligence offers information on technology, applications, processes, dashboards and other key tools entrepreneurs require to be successful and organisations require to successfully transform themselves. Disruption comes from new market creation. The creation of a new market is a common occurrence when investigating disruptive companies. Creating a new market, which solves the needs of customers across a variety of existing markets, can be crucial to incumbent organisations sustaining their success. Organisations creating new markets and obtaining a large share of that market, while negatively impacting on the performance of organisations in other, related markets, can cause a great deal of disruption. Disruption comes from existing markets. Disruption from within alreadyestablished markets is an alternative, but equally common, approach to causing disruption for organisations which are incumbent to that market. When there is a number of organisations operating within and profiting from the same market, competitor activity may disrupt the market they know and capitalize off of, could be fundamentally changed. Production competence comes from technology. The ability of an organisation to produce competently is based on a variety of mechanisms. And technology is at the centre of these mechanisms. Maintaining production competence in industries where competitors are constantly improving their technology can be harmful to organisations who are not improving their technology. There are a number of barriers 
to the initial adoption of technology as well as to improving existing technology, but the challenges of these changes could be outweighed by the negative effects that the failure to change carries.

Costs of adoption are a primary negative. There is a multitude of possible reasons why organisations do not want to adopt new technologies, techniques or operating methods. Chief among these reasons is that of cost. The inordinate costs associated with both adopting new technologies or operational methods, as well as improving on existing technology or operational methods, is the principal reason organisations are reluctant to digitally transform. Technology improves compatibility and working between organisations. Communication, mutual operation and successful interactions between organisations is facilitated and improved by technology. Traditional channels of business are supplemented with technology, where organisations which rely on each other have superior means of communication and operational efficiency stemming from their use of supporting technology. Digitisation allows for virtual teamwork. Traditionally, employees would have face-to-face interactions with one another at a physical workplace. However, owing to digitisation, organisations are now able to create virtual teams, which have the potential to span a city, a country, or the globe. As a result, teams can cooperate with one another at anytime from anywhere in the world without having to physically meet. This allows for new perspective, ways of working, problem solving and round-the-clock working on the same projects as well as more flexibility and employee freedom.

\section{Digital Entrepreneurship and Digital Transformation Characteristics}

In order to report the findings of the SLR, we utilised the Dynamic Capabilities Theory which refers to the "ability to integrate, build, and reconfigure internal and external competencies to address rapidly-changing environments" [47: 9]. The dynamic capabilities approach emphasises organisational and strategic capabilities to realise competitive advantage and consists of three main components of capabilities: (1) to sense and shape opportunities and threats (sensing), (2) to seize opportunities (seizing), and (3) to maintain competitiveness through enhancing, combining, protecting, and, when necessary, reconfiguring the organisation's intangible and tangible assets ("transforming" or "shifting") [47]. By mapping the characteristics identified (Table 2) to the 3 main components of the dynamic capabilities based on the definitions and scope of each, the particular feature and attribute set of digital entrepreneurship and digital transformation are depicted in Table 3.

The aim of this paper was to consider the characteristics of digital entrepreneurship and digital transformation as they are not mutually exclusive (Sect. 2.3). Characteristics pertinent to sensing and shaping opportunity includes the creation of self-employment through prospects based on an entrepreneurs' drive to succeed. Digital transformation in this instance provides opportunities to create new markets or to optimise existing collaborations and the understanding of digitisation may shape additional prospects. Digitisation enables digital entrepreneurship and digital transformation. The management, and the successful implementation thereof, is what allows for lucrative digital 
Table 3. Digital entrepreneurship and digital transformation characteristics mapped to dynamic capabilities [47]

\begin{tabular}{l|l|l}
\hline Sensing & Seizing & Transforming or shifting \\
\hline Self-employment & $\begin{array}{l}\text { Entrepreneurship can } \\
\text { come from opportunity }\end{array}$ & Work satisfaction \\
\hline Entrepreneurship prospect & $\begin{array}{l}\text { Traditional } \\
\text { organisational } \\
\text { structures may slow } \\
\text { progress }\end{array}$ & Entrepreneurial traits \\
\hline Entrepreneurship aspiration & $\begin{array}{l}\text { E-strategies bolster } \\
\text { competitive advantage }\end{array}$ & $\begin{array}{l}\text { Digitisation allows for better } \\
\text { relationships }\end{array}$ \\
\hline $\begin{array}{l}\text { Disruption comes from new } \\
\text { market creation }\end{array}$ & $\begin{array}{l}\text { Disruption comes from } \\
\text { existing markets }\end{array}$ & $\begin{array}{l}\text { Digitisation does not mean } \\
\text { success is clear and easy to } \\
\text { entrepreneurs }\end{array}$ \\
\hline $\begin{array}{l}\text { Technology improves } \\
\text { compatibility and working } \\
\text { between organisations }\end{array}$ & $\begin{array}{l}\text { Production competence } \\
\text { comes from technology }\end{array}$ & $\begin{array}{l}\text { Employee involvement is } \\
\text { crucial }\end{array}$ \\
\hline $\begin{array}{l}\text { Understanding digitisation is } \\
\text { critical }\end{array}$ & & Knowledge management \\
\hline & & $\begin{array}{l}\text { Business intelligence can } \\
\text { facilitate entrepreneurship and } \\
\text { transformation }\end{array}$ \\
\hline $\begin{array}{l}\text { Cost of technology } \\
\text { Technology adoption }\end{array}$ \\
\hline $\begin{array}{l}\text { Digitisation allows for virtual } \\
\text { teamwork }\end{array}$ \\
\hline
\end{tabular}

entrepreneurship and digital transformation to take place. Characteristics relevant to seizing opportunity are based on an entrepreneurs' ability to exploit prospects that may be derived from existing market- or digital transformation strategies. The potential of technology in improving productivity also presents opportunity. Technology is employed, in some form or another, by incumbent organisations which dominate markets, start-ups, entrepreneurs and by those who are transforming organisations. The fact that traditional organisations may slow down progress is highlighted as a characteristic to be aware of in a digital entrepreneurship endevour. Characteristics applicable to maintaining competitiveness include features pertaining to an entrepreneur profile such as traits, work satisfaction, relationships, collaboration, technology adoption and the management of knowledge. The facilitative role of data and business intelligence on entrepreneurship and transformation, must be considered and the cost of adoption is a characteristic highlighting potential drawbacks to be cognisant of.

Table 3 illustrates that a number of characteristics need to be considered in order to achieve digital entrepreneurship enabled through digital transformation, signifying the relationship existing between them. By taking the characteristics into account, both 
organisations as well as individuals can consider creating new business ventures or transform existing enterprises by creating, or making use of, innovative technologies.

\section{Conclusion}

The purpose of this paper was to consider the characteristics of digital entrepreneurship and digital transformation. After investigating and analysing entrepreneurship and digital transformation to determine a clearer understanding of what these concepts entail, a SLR was conducted. Twenty-one characteristics were identified and presented using the Dynamic Capabilities Theory, illustrating the key features and attributes of digital entrepreneurship and digital transformation.

By referencing the data from this study, both individuals and companies can garner a firmer grasp on what these concepts entail and how they can add value to intellectual and practical knowledge. This paper contributed by highlighting a number of key characteristics which exist for each digital entrepreneurship and digital transformation, with focus on how these characteristics relate. By making use of the proposed conceptual framework, individuals and organisations alike can either start new companies or adapt existing ones to be aligned with the digital age.

As this study focused on identifying the characteristics of digital entrepreneurship and digital transformation, the proposed findings may be tested in a real-world situation within and organisation, with entrepreneurs or with an idea incubator and accelerator. Through such a process, the proposed characteristic set may be enriched.

\section{References}

1. Gohmann, S.F.: Institutions, latent entrepreneurship, and self-employment: an international comparison. Entrep. Theory Pract. 36(2), 295-321 (2012)

2. Giones, F., Brem, A.: Digital technology entrepreneurship: a definition and research agenda. Technol. Innov. Manag. Rev. 7(5), 44-51 (2017)

3. Kraus, S., et al.: Digital entrepreneurship: a research agenda on new business models for the twenty-first century. Int. J. Entrep. Behav. Res. 25, 353-375 (2019)

4. Autio, E., et al.: Digital affordances, spatial affordances, and the genesis of entrepreneurial ecosystems. Strat. Entrep. J. 12(1), 72-95 (2018)

5. Richter, C., et al.: Digital entrepreneurship: innovative business models for the sharing economy. Creat. Innov. Manag. 26(3), 300-310 (2017)

6. Hess, T., et al.: Options for formulating a digital transformation strategy. MIS Q. 15(2), $123-$ 139 (2016)

7. Bounfour, A.: Digital Futures, Digital Transformation. PI. Springer, Cham (2016). https:// doi.org/10.1007/978-3-319-23279-9

8. Boneva, M.: Challenges related to the digital transformation of business companies. In: Proceedings of the 6th International Conference Innovation Management, Entrepreneurship and Sustainability. University of Economics, Prague. pp. 101-114 (2018)

9. Zhu, K., et al.: Innovation diffusion in global contexts: determinants of post-adoption digital transformation of European companies. Eur. J. Inf. Syst. 15, 601-616 (2006) 
10. Dutot, V., Van Horne, C.: Digital entrepreneurship intention in a developed vs. emerging country: an exploratory study in France and the UAE. Transnatl. Corp. Rev. 7(1), 79-96 (2015)

11. Rashidi, R., et al.: Presenting a butterfly ecosystem for digital entrepreneurship development in knowledge age. In: 7th International Conference on Application of Information and Communication Technologies. IEEE, Baku (2013)

12. Najda-Janoszka, M.: Matching imitative activity of high-tech firms with entrepreneurial orientation. J. Entrep. Manag. Innov. 9(1), 52-67 (2012)

13. Darnihamedani, P., Hessels, J.: Human capital as a driver of innovation among necessitybased entrepreneurs. Int. Rev. Entrep. 14(1), 1-23 (2016)

14. Davidson, E., Vaast, E.: Digital entrepreneurship and its sociomaterial enactment. In: Proceedings of the Annual Hawaii International Conference on System Sciences, pp. 1-10. IEEE (2010)

15. Rindova, V., Barry, D., Ketchen, D.J.J.: Entrepreneuring as emancipation. Acad. Manag. Rev. 34, 477-491 (2009)

16. Dy, A.M., Martin, L., Marlow, S.: Emancipation through digital entrepreneurship? A critical realist analysis. Organization 25, 585-608 (2018)

17. Cuervo, Á., Ribeiro, D., Roig, S.: Entrepreneurship: concepts, theory and perspective. Introduction. In: Cuervo, Á., Ribeiro, D., Roig, S. (eds.) Entrepreneurship. Springer, Heidelberg (2007). https://doi.org/10.1007/978-3-540-48543-8_1

18. Shane, S., Venkataraman, S.: The promise of entrepreneurship as a field of research. Acad. Manag. Rev. 25, 217-226 (2000)

19. Rowley, J.: From learning organisation to knowledge entrepreneur. J. Knowl. Manag. 4, $7-$ $15(2000)$

20. Maguire, S., Hardy, C., Lawrence, T.B.: Institutional entrepreneurship in emerging fields: HIV/Aids treatment advocacy In Canada. Acad. Manag. J. 47, 657-679 (2004)

21. Hull, C.E., et al.: Taking advantage of digital opportunities: a typology of digital entrepreneurship. Int. J. Netw. Virtual Organ. 4, 290-303 (2007)

22. Gale, M., Aarons, C.: Digital transformation: delivering on the promise. Lead. Lead. 2018, 30-36 (2018)

23. Bowersox, D.J., Closs, D.J., Drayer, R.W.: The digital transformation: technology and beyond. Supply Chain Manag. Rev. 9, 22-29 (2005)

24. Bharadwaj, A.S., et al.: Digital business strategy: toward a next generation of insights. MIS Q. 37, 471-482 (2013)

25. Matt, C., Hess, T., Benlian, A.: Digital transformation strategies. Bus. Inf. Syst. Eng. 57, 339-343 (2015)

26. Kane, G.C., et al.: Strategy, not technology, drives digital transformation. MIT Sloan Manag. Rev. (2015). https://sloanreview.mit.edu/projects/strategy-drives-digital-transformation/

27. Thornton, P.H.: The sociology of entrepreneurship. Annu. Rev. Sociol. 25, 19-46 (1999)

28. Christensen, C.M., Johnson, M.W., Rigby, D.K.: Foundations for growth: how to identify and build disruptive new businesses. MIT Sloan Manag. Rev. 43, 22-32 (2002)

29. Aromataris, E., Pearson, A.: The systematic review: an overview. AJN Am. J. Nurs. 114, 53-58 (2014)

30. Rouhani, B.D., et al.: A systematic literature review on enterprise architecture implementation methodologies. Inf. Softw. Technol. 62, 1-20 (2015)

31. Characteristic. BusinessDictionary.com. http://www.businessdictionary.com/definition/ characteristic.html. Accessed 05 Jan 2020

32. Blanchflower, D.G., Oswald, A.J.: What makes an entrepreneur? J. Labor Econ. 16, 26-60 (1998) 
33. Bogdanowicz, M.: Digital entrepreneurship barriers and drivers the need for a specific measurement framework (2015)

34. Ebert, C., Duarte, C.H.C.: Digital transformation. IEEE Softw. 35, 16-21 (2018)

35. Hair, N., et al.: Market orientation in digital entrepreneurship: advantages and challenges in a Web 2.0 networked world. Int. J. Innov. Technol. Manag. 9, 18 (2012)

36. Liao, A., Hull, C.E., Sriramachandramurthy, R.: The six facets model of technology management: a study in the digital business industry. Int. J. Innov. Technol. Manag. 10, 124 (2013)

37. Minniti, M., Lévesque, M.: Entrepreneurial types and economic growth. J. Bus. Ventur. 25, 305-314 (2010)

38. Nambisan, S.: Digital entrepreneurship: toward a digital technology perspective of entrepreneurship. Entrep. Theory Pract. 41, 1029-1055 (2017)

39. Berman, S.J.: Digital transformation: opportunities to create new business models. Strat. Lead. 40, 16-24 (2016)

40. Schuchmann, D., Seufert, S.: Corporate learning in times of digital transformation: a conceptual framework and service portfolio for the learning function in banking organisations. Int. J. Autom. Comput. 8, 31-39 (2015)

41. Christensen, C.M., Verlinden, M., Westerman, G.: Disruption, disintegration and the dissipation of differentiability. Ind. Corp. Change 11, 955-993 (2002)

42. Lee, G.-G., Bai, R.-J.: Organizational mechanisms for successful IS/IT strategic planning in the digital era. Manag. Decis. 41, 32-42 (2003)

43. Nerkar, A.D.: Business Analytics (BA): Core of Business Intelligence (BI). Int. J. Adv. Eng. Manag. Sci. 2, 2176-2178 (2016)

44. Piccinini, E., et al.: Transforming industrial business: the impact of digital transformation on automotive organizations. In: Thirty Sixth International Conference on Information Systems, pp. 1-20 (2015)

45. Chambers, C.: Technological advancement, learning, and the adoption of new technology. Eur. J. Oper. Res. 152, 226-247 (2004)

46. Resca, A., Za, S., Spagnoletti, P.: Digital platforms as sources for organizational and strategic transformation: a case study of the midblue project. J. Theor. Appl. Electron. Commer. Res. 8, 71-84 (2013)

47. Teece, D., Peteraf, M., Leih, S.: Dynamic capabilities and organizational agility: risk, uncertainty, and strategy in the innovation economy. Calif. Manag. Rev. 58(4), 13-35 (2016) 